\title{
Reflexões sobre a formação do terapeuta ocupacional para o papel docente: experiência do programa de aperfeiçoamento de ensino - PAE
}

\section{Reflexions on the academic training of the occupational therapist for the teaching role: experience of the program of teaching improvement - PAE}

\author{
Francine Baltazar Assad ${ }^{1}$, Regina Célia Fiorati ${ }^{2}$
}

http://dx.doi.org/10.11606/issn.2238-6149.v24i1p67-72

Assad FB, Fiorati RC. Reflexões sobre a formação do terapeuta ocupacional para o papel docente: experiência do programa de aperfeiçoamento de ensino - PAE. Rev Ter Ocup Univ São Paulo. 2013 jan./abr.;24(1): 67-72.

RESUMO: Frente ao crescimento de cursos de graduação em Terapia Ocupacional no país, a carreira acadêmica se constituiu como novo campo de atuação. Nas últimas décadas houve aumento significativo pela procura por cursos de pós-graduação strictusensu e os profissionais têm buscado aprimoramento para a carreira docente. O estudo visa refletir sobre a formação de terapeutas ocupacionais para a docência, a partir da experiência do estágio supervisionado em docência no Programa de Aperfeiçoamento de Ensino, junto a uma disciplina de graduação em Terapia Ocupacional na Universidade de São Paulo, durante o $1^{\circ}$ semestre de 2012. A experiência foi relatada de acordo com as atividades desenvolvidas: organizativas, técnicas, didático-pedagógicas, das relações professor/aluno e avaliativas. Percebeu-se que as atividades vivenciadas são essenciais na formação para a docência. Além disso, essa formação precisa ser estimulada para além da pesquisa, inserindo uma preparação pedagógica nos cursos de pós-graduação e graduação. As atividades de pesquisa, ensino e extensão desenvolvidas pelos docentes devem se articular sob uma perspectiva integral, promovendo os espaços de ensino-aprendizagem em espaços de reflexão, transformação e significação.

DESCRITORES: Terapia Ocupacional; Educação superior; Educação de pós-graduação.
Assad FB, Fiorati RC. Reflexions on the academic training of the occupational therapist for the teaching role: experience of the program of teaching improvement - PAE. Rev Ter Ocup Univ São Paulo. 2013 jan./abr.;24(1): 67-72.

ABSTRACT: Taking into consideration the growth in the graduation courses of Occupational Therapy in the country, the academic career was as a new field of action. In recent decades there has been an increase for the search of strictu-sensu post graduation and professionals have sought improvement to the teaching career. The study aims to reflect on the training of occupational therapists to teaching, from the experience of the supervised training on teaching in the Program of Teaching Improvement, with a graduate course in Occupational Therapy at University of São Paulo, during the first semester of 2012. The experience was reported according to the activities developed: organizational, didactic-pedagogical, technical, teacher/student relations and evaluation. It was noticed that the activities experienced are essential in teaching training. In addition, this training needs to be encouraged beyond the research, including a pedagogical preparation in the graduation and post graduation courses. The research activities, teaching and extension, developed by the teachers must merge under an integral perspective, promoting the teaching-learning spaces in the reflection, changing and meaning spaces.

KEY WORDS: Occupational therapy; Education, higher; Education, graduate.

\footnotetext{
1. Terapeuta Ocupacional; Doutoranda em Ciências - Programa Enfermagem Psiquiátrica-EERP-USP; e-mail: franassad@hotmail.com

2 Docente do Curso de Terapia Ocupacional da Faculdade de Medicina de Ribeirão Preto - USP; e-mail: reginacf@fmrp.usp.br

Endereço para correspondência: Rua das Acácias 663, Vila Lídia, Batatais, SP. CEP: 14300-000
} 


\section{INTRODUÇÃO}

$\mathrm{N}$ as últimas décadas, decorrentes das mudanças na política de educação superior no Brasil, houve grande crescimento de cursos de graduação em terapia ocupacional e abertura de programas de pós-graduação strictu-sensu, esse crescimento aconteceu especialmente nas universidades federais e na região sudeste, ao mesmo tempo, um número excessivo de cursos privados foram fechados ${ }^{10,12,16}$. Assim, com o crescimento de cursos de graduação houve novas possibilidades no mercado de trabalho, contudo, surge a necessidade de um maior engajamento dos terapeutas ocupacionais para a representatividade da produção de conhecimento científico no cenário nacional, para além de ocupar espaços no ensino e pesquisa. Assim, é relevante a discussão do papel do terapeuta ocupacional enquanto docente e como tem sido o preparo para essa função.

Como já ressaltado, na região sudeste brasileira ocorre a maior concentração de cursos de graduação em terapia ocupacional, programas de pós-graduação e grupos de pesquisa na área ${ }^{10}$. Estudos sobre a implantação desses programas apontam caminhos e discussões para o âmbito da pesquisa em terapia ocupacional no Brasi ${ }^{2,3,9,10,12}$, e, sobre a importância da formação strictu-sensu devido ao aumento dos cursos de graduação e pressão das universidades para esta formação ${ }^{6}$, porém não discutem a importância da formação do terapeuta ocupacional enquanto educador no ensino superior. Apenas um discute sobre o papel do terapeuta ocupacional enquanto professor universitário ${ }^{16}$, apontando que são quatro os papéis sociais, o de docente, pesquisador, administrador e também nos espaços de atividades de extensão ${ }^{16}$.

Para tanto, os profissionais de diversas áreas, incluindo os terapeutas ocupacionais, que optam por seguirem a carreira docente, precisam buscar conhecimentos técnicos pedagógicos e específicos para este papel. A realidade mostra que essa busca é realizada em nível de pós-graduação. No cenário nacional a formação de professores para o ensino superior vem ganhando força, em decorrência da importância do ensino nos cursos de graduação e frente ao despreparo dos docentes para essa atividade ${ }^{1}$. Atualmente os mestres e doutores são mais capacitados para o desenvolvimento de pesquisas, consequentemente são menos preparados para a educação em nível superior, predominando o despreparo do que seja o processo de ensino e de aprendizagem ${ }^{13}$. Nesse sentido, os professores universitários acumulam conhecimento na área de sua especialidade, mas carecem de conhecimento para a experiência didático-pedagógica ${ }^{14}$.
Nesse contexto, na Universidade de São Paulo (USP) os programas de pós-graduação oferecem aos pósgraduandos o Programa de Aperfeiçoamento de Ensino (PAE), no qual os pós-graduandos têm a oportunidade de aprimorarem e desenvolverem habilidades e atividades pedagógicas para o ensino superior. Assim, esse trabalho busca mostrar a importância desse programa para a formação do terapeuta ocupacional como professor universitário, ressaltando-se a necessidade da articulação do programa PAE como dispositivo de produção de conhecimento para o campo pedagógico, superando a situação de excessiva concentração do saber apenas na área de especialidade do docente, em detrimento de conhecimentos na área do ensino e campo pedagógico.

Neste estudo será dado enfoque na $2^{\mathrm{a}}$ etapa do PAE, o Estágio Supervisionado em Docência.

\section{O Programa de Aperfeiçoamento de Ensino}

O Programa de Aperfeiçoamento de Ensino oferecido pela USP foi instituído pela Portaria GR 3347, de 09 de fevereiro de 1995 e está regulamentado pela Portaria GR 3588, de 10 de maio de 2005, destina-se exclusivamente a alunos de pós-graduação matriculados na USP nos cursos de mestrado e doutorado. Seu principal objetivo é aprimorar a formação do pós-graduando para atividade didática de graduação e sua composição consiste em duas etapas: Preparação Pedagógica e Estágio Supervisionado em Docência. Ao final do estágio, depois de cumpridas as formalidades, os participantes que obtêm aproveitamento satisfatório têm direito a um certificado e, a critério da Comissão de Pós-Graduação, poderão receber créditos pela atividade. O Programa é opcional aos alunos de Pós-Graduação da Universidade, exceto àqueles que são contemplados pela Bolsa Demanda Social da CAPES, cujo regulamento solicita a realização de estágio. O estágio possui uma carga horária de até seis horas semanais ${ }^{18}$.

$\mathrm{Na}$ segunda etapa referente ao estágio, as diretrizes ${ }^{19}$ caracterizam a participação do estudante de pós-graduação nas seguintes atividades:

a) Organizativa: seleção dos conteúdos curriculares e da bibliografia de apoio, seleção e organização dos recursos didáticos e outros materiais de apoio, etc;

b) Técnica: organização das atividades operacionais como lista de presença e de notas e acompanhamento das atividades práticas e teóricas, etc;

c) Didático-pedagógica: organização e desenvolvimentos das aulas e utilização do espaço-tempo das atividades didáticas, etc;

d) Das relações professor/aluno: favorecendo 
a organização da participação dos alunos nas aulas e atividades, estabelecimento de vocábulo adequado, e demais iniciativas que facilitem a interlocução entre o docente e os estudantes etc;

e) Avaliativa: ações como a seleção dos tipos mais adequados de avaliação e elaboração de instrumentos de avaliação, bem como a definição dos critérios avaliativos etc.

\section{OBJETIVO}

Refletir sobre a formação de terapeutas ocupacionais para a docência, a partir da experiência durante um Estágio Supervisionado em Docência no Programa de Aperfeiçoamento de Ensino (PAE).

\section{A EXPERIÊNCIA DO ESTÁGIO SUPERVISIONADO EM DOCÊNCIA}

O estágio foi realizado junto a disciplina Dinâmica e Abordagens Grupais e Terapia Ocupacional no curso de graduação em Terapia Ocupacional da Faculdade de Medicina de Ribeirão Preto-USP, sob supervisão da docente responsável.

O estágio teve duração de cinco meses, com carga horária de seis horas semanais, perfazendo um total de 120 horas, durante o $1^{\circ}$ semestre de 2012. A escolha da disciplina para a realização do estágio é livre, portanto, a estagiária escolheu a que mais se identificava, dentre as várias oferecidas pelo PAE. Como o processo seletivo para esta disciplina oferecia uma vaga para estagiário PAE, apenas uma estagiária foi selecionada. Vale ressaltar que, anteriormente ao Estágio Supervisionado em Docência, foi realizada a $1^{\mathrm{a}}$ etapa de Preparação Pedagógica, a qual consistiu em cursar, no Programa de Pós-graduação da Escola de Enfermagem de Ribeirão Preto-USP, as disciplinas Paradigmas Pedagógicos da Prática Docente em Saúde e, Educação em Saúde, segundo a Pedagogia da Problematização.

A disciplina, na qual o estágio foi desenvolvido, tinha por finalidade instrumentalizar o aluno de graduação para o conhecimento e uso dos diversos tipos de grupos e sua aplicabilidade na Terapia Ocupacional. Foi ministrada para uma turma de 20 alunos do $3^{\circ}$ ano letivo, ocorreu uma vez por semana, com três horas de duração. O restante das horas, correspondentes à carga horária total do estágio, foram distribuídas em atividades diversas que serão relatadas a seguir.

O relato será apresentado de acordo com as cinco atividades previstas pelas diretrizes do PAE, sobre a participação do estudante de pós-graduação no estágio, são elas: organizativa; técnica; didático-pedagógica; das relações professor/aluno e, avaliativa.

\section{Atividades organizativas}

As atividades do estágio, inicialmente, dirigiramse para a realização de atividades organizativas, as quais envolveram participação em reuniões com a docente responsável para planejamento das aulas e preparação do material didático, anteriormente ao início das aulas e, pesquisa bibliográfica. Durante esta etapa, foi dada à estagiária a oportunidade para sugerir mudanças no cronograma e nas referências bibliográficas utilizadas, estabelecendo trocas junto ao docente supervisor.

\section{Atividades técnicas}

A estagiária envolveu-se com as atividades técnicas, como a organização da lista de presença, a elaboração de critérios para as notas das atividades desenvolvidas e, acompanhamento das atividades práticas e teóricas, auxiliando os alunos na elaboração de seminários e nas visitas aos campos de observação.

\section{Atividades didático-pedagógicas}

As atividades didático-pedagógicas foram as mais significativas, pois houve uma participação ativa da estagiária, tanto no auxílio das discussões em sala, referente ao conteúdo trabalhado na disciplina, quanto na elaboração destes conteúdos e de estratégias de ensino-aprendizagem. A participação envolveu a operacionalização, organização e desenvolvimento das aulas.

\section{Atividades relações professor/aluno}

Em muitos momentos, a estagiária estabeleceu um papel de articuladora entre a docente responsável e os alunos, auxiliando os alunos no incentivo à participação das atividades propostas, na organização para os pequenos grupos de discussão e esclarecimento de dúvidas, estabelecendo um forte vínculo entre docente/aluno/estagiária.

Atividades avaliativas

As atividades avaliativas envolveram o auxílio na correção de trabalhos, seminários e avaliação final do aluno.

REFLEXÕES SOBRE A FORMAÇÃO PARA A DOCÊNCIA 
A participação no PAE suscitou questionamentos que serão apresentados com a proposta de discutir alguns princípios relevantes sobre a formação de terapeutas ocupacionais para a docência.

Apesar das diretrizes curriculares apontarem o ensino como uma das competências para o exercício da profissão é observado que os cursos de graduação em terapia ocupacional no Brasil são estruturados para a formação assistencial e, as atividades de ensino, que envolvam a educação em nível superior, não estão inseridas na grade curricular.

Entretanto, é competência e habilidades gerais do terapeuta ocupacional a educação permanente, cujo objetivo é desenvolver o aprendizado contínuo tanto na formação quanto na prática ${ }^{4}$. Assim, para os profissionais que optam por seguir a carreira docente, a busca pelo aprimoramento nesta área é essencial para o desenvolvimento deste papel.

Alguns elementos essenciais da atuação docente são desconhecidos pelos professores, como a relação da disciplina com o projeto do curso, planejamento, organização da aula, metodologias e estratégias didáticas, avaliação, peculiaridades da interação professor-aluno ${ }^{1}$, entretanto, o estágio relatado propiciou o desenvolvimento dessas habilidades essenciais para o desenvolvimento da docência. Foi possível vivenciar, questionar e refletir em relação a metodologias de ensino-aprendizagem, de tecnologias de construção do conhecimento em sala de aula, bem como de técnicas de avaliação processual dos alunos, contribuindo efetivamente, não apenas com a aprendizagem dos alunos no que diz respeito ao conteúdo específico da disciplina, mas também com a docente coordenadora propiciando a reflexão, discussão e inserção de metodologias de ensino-aprendizagem através da inserção direta nas atividades didático-pedagógicas. Para tanto, a oportunidade de formação no PAE durante a pós-graduação é de grande relevância para a formação de educadores em nível superior e um espaço rico para a aprendizagem teórico-prática para os terapeutas ocupacionais que pretendem seguir carreira docente.

A preocupação atual, sobre uma efetiva inserção da terapia ocupacional no cenário científico, é necessária e tem sido foco de discussão de pesquisadores da área ${ }^{10}$, porém é preciso também chamar a atenção para outras funções exercidas na carreira docente e essenciais para a formação de novos profissionais, a de educador e facilitador do ensino-aprendizagem.

Há o domínio do conhecimento no que diz respeito a especialidade do docente, devido a grande ênfase para o desenvolvimento da pesquisa como a principal atividade docente, e pouco incentivo para o aprofundamento de sua formação pedagógica, o que sugere, num consenso, de que a docência no ensino superior não requer formação para o ensino, predominando o conhecimento da especialidade, caracterizado pelo exercício da pesquisa ${ }^{13,20}$. A atividade de pesquisa é essencial para a produção do conhecimento e para a não paralisação da atividade docente dentro de uma perspectiva de mera transferência de componentes culturais ou profissionais. Entretanto, o nível da formação oferecida aos alunos tem constituído uma variável de menor importância ${ }^{20}$.

Cabe então refletir e discutir sobre o papel docente do terapeuta ocupacional enquanto educador no processo ensino-aprendizagem. O educador precisa lutar por uma educação que apresente um programa de estudos e vivências com a atenção voltada para as integrações de significados e não para a acumulação passiva de conhecimento, criando espaços para a produção e construção do conhecimento. Deve propiciar o meio adequado para que os educandos assumamse enquanto atores sociais e, principalmente transformadores da realidade ${ }^{7}$. Além disso, o educador também precisa apresentar-se como um agente de mudança para enfrentar situações problemas em determinados contextos, nos quais ele saiba não só o que fazer e como fazer, mas também por que e para que fazê-lo ${ }^{1}$. Corroborando com os propósitos das competências e habilidades específicas do terapeuta ocupacional, enquanto agente facilitador, transformador e integrador junto às comunidades ${ }^{4}$. Esse papel de facilitador pôde ser vivenciado pela estagiária, principalmente, nas atividades didático-pedagógicas e das relações professor/ aluno.

Conforme já citado anteriormente, o terapeuta ocupacional enquanto professor universitário ocupa quatro papéis sociais, o de docente, pesquisador, administrador e também nos espaços de atividades de extensão ${ }^{16}$, entretanto, estes papéis precisam ser articulados entre si, como apontado no VI Encontro Latino-americano de Escolas e Docentes de Terapia Ocupacional, produzindo conexões produtivas entre eles ${ }^{12}$. Entende-se que essa articulação minimiza a dicotomia existente entre esses âmbitos da atividade docente e transforma o ensino também em atividade de produção de conhecimento científico e não apenas em transferência passiva do conhecimento. Essa aproximação deve-se ampliar para além dos programas de iniciação científica que acabam sendo pontuais e contemplando poucos alunos, mas deve ser inserida também nos Programas Políticos Pedagógicos dos cursos de graduação. É necessário superar a fragmentação das múltiplas atividades dos docentes, as quais predominam, de forma intensa, aquelas voltadas para a pesquisa em detrimento das de ensino e extensão ${ }^{1}$. A articulação entre docência, pesquisa, administração e 
extensão, foram aprofundados e discutidos em diversos momentos de supervisão e envolvimento com a docente supervisora.

Assim, os papéis exercidos por este profissional, tanto na assistência, na pesquisa quanto na docência, se inter-relacionam e mantém objetivos comuns, como o de possibilitar espaços de produção de significados. Dessa forma, a educação também deve ser compreendida como um processo de humanização, o qual possibilita as pessoas se inserirem numa sociedade em construção ${ }^{13}$.

Entende-se, portanto, que cabe ao terapeuta ocupacional apropriar-se dos objetivos de suas funções assistenciais nos campos da saúde, educação e social, e imprimi-las na sua atuação como educador. Nesse sentido, um estudo se propôs a apresentar e discutir trabalhos, como os de Mosey, Benetton e outros, que valorizam o processo educativo como inerente ao processo da terapia ocupaciona ${ }^{11}$. Nessa perspectiva, foi possível proporcionar contextos de ensino-aprendizagem que se articularam com o saber-fazer da profissão, pelo fato da estagiária ser terapeuta ocupacional e o estágio estar inserido em um curso de graduação em terapia ocupacional. Por isso a importância do programa PAE de fornecer a este profissional uma instrumentalização, incluindo apreensão de novas metodologias de ensino.

Dessa forma, é necessária a discussão do papel de educador do ensino superior. Em algumas instituições de ensino ainda prevalece a formação tradicional, na qual o professor exerce o papel de detentor do conhecimento, consequentemente este modelo faz pouca correlação com as necessidades de saúde, sociais, de trabalho e educacionais da população, o que implica nas práticas desses profissionais ${ }^{15}$. Nas atividades didático-pedagógicas, algumas estratégias não tradicionais, apreendidas na $1^{\text {a }}$ etapa de preparação pedagógica, foram utilizadas, tais como discussão em pequenos grupos, técnicas de jogos teatrais, dinâmicas e observação dos campos de atuação, em articulação com aulas expositivas, assim, pôde-se vivenciar diferentes estratégias de ensino-aprendizagem.

$\mathrm{Na}$ atualidade é importante também a reflexão sobre como conduzir o ensino e a formação profissional em sintonia com as transformações e necessidades da sociedade?

A globalização, a busca por conhecimento e o aceleramento da vida estão presentes na sociedade do século XXI, e indicam que a formação profissional deve promover a estimulação da autonomia e da cidadania dos indivíduos e grupos assistidos. Ocorre que frente às características da atualidade, essa tarefa torna-se difícil de ser acessada, o que sugere a transformação do papel do professor no processo de ensino-aprendizagem, com a inclusão de novas perspectivas tecnológicas e metodológicas ${ }^{5}$. Portanto, há a necessidade de uma constituição de um novo paradigma de docência universitária, o que requer novas capacidades dos docentes, favorecendo o desenvolvimento de outras dimensões na formação dos alunos ${ }^{1}$.

Neste sentido, a educação deve constituir-se numa práxis educativa integrada à dinâmica cotidiana do indivíduo, promovendo a ampliação dos horizontes e a autonomia das ações e o desenvolvimento da consciência crítico-reflexiva de si, do outro e do meio ${ }^{17}$. Portanto, é importante a incorporação de práticas pedagógicas que estimulem reflexões contextuais da realidade e priorizem um processo de ensino-aprendizagem integrado. Algumas políticas públicas têm preconizado este tipo de formação profissional tanto em ações de saúde, bem como na educação e na assistência social ${ }^{8}$.

Assim, o papel do educador no processo de formação do terapeuta ocupacional deve ser de auxiliar os alunos no processo de percepção e concepção das relações entre as partes do conhecimento e a relação destas com o todo, considerando todas as dimensões humanas, visto que para a busca da autonomia de indivíduos, grupos e/ou comunidades, é necessário que se considere as diversas dimensões humanas 5 .

É necessário que este processo de ensino-aprendizagem ocorra no sentido de mão-dupla, produzindo transformações no papel do educador e do educando, o que sugere mudanças de paradigmas, reformulações e adaptações nos Projetos Políticos Pedagógicos, o que já vem acontecendo em algumas instituições do país. Desta forma, os currículos precisam ser orientados com uma base integrada e interdisciplinar e possuirem em sua organização uma estrutura que possibilite a articulação entre teoria e prática ${ }^{15}$.

\section{CONSIDERAÇÕES FINAIS}

Em todas as atividades realizadas no estágio, foi possível o desenvolvimento do ensino prático e teórico, a colaboração no que diz respeito à competência profissional como terapeuta ocupacional e, a promoção de contextos para o aprendizado dos alunos. Além disso, o estágio supervisionado em docência proporcionou espaço de aprendizado para o estudante de pós-graduação em relação ao modus operandi do docente frente às diversidades dos alunos, reconhecimento e realização de técnicas pedagógicas apreendidas na $1^{\mathrm{a}}$ etapa de preparação pedagógica, considerando a necessidade de incorporar práticas pedagógicas integradas e articuladas com os contextos, nos quais o terapeuta ocupacional pode estar inserido.

Assim, ao procurarem por cursos de pós-graduação strictu-sensu, cabe aos pós-graduandos, elegerem disciplinas e cursos que discutam a importância do ensino superior e do 
papel de educador, tal como proposto pelo PAE, contribuindo para a formação deste profissional.

Para tanto, a preparação para a carreira docente do terapeuta ocupacional deve ser pautada em estratégias que articulem as ações de pesquisa e ensino às de assistência, direcionando esta formação para o entendimento de uma educação integrada, na qual educadores de ensino superior promovam espaços de reflexão, transformação e significados.

\section{REFERÊNCIAS}

1. Almeida MI, Pimenta SG. A construção da pedagogia universitária no âmbito da Universidade de São Paulo. In: Pimenta SG, Almeida MI, organizadores. Pedagogia Universitária: caminhos para a formação de professores. São Paulo: Cortez; 2011. p.19-43.

2. Ballarin MLGS, Toldrá RC. A trajetória do pesquisador e da iniciação científica no curso de graduação em terapia ocupacional da PUC-Campinas. Cad Ter Ocup UFSCar. 2001;9(2):67-79.

3. Barros DD, Oliver FC. Contribuição para a discussão do Qualis de terapia ocupacional no Brasil. Rev Ter Ocup Univ São Paulo. 2003;14(2):52-63.

4. Brasil. Ministério da Educação. Conselho Nacional de Educação. Camâra de Educação Superior. Resolução CNE/ CES 6, de 19 de fevereiro de 2002. Institui Diretrizes Curriculares Nacionais do Curso de Graduação em Terapia Ocupacional [citado 2 ago. 2012]. Disponível em: http:// portal.mec.gov.br/cne/arquivos/pdf/CES062002.pdf.

5. Britto CMD. Formação do Terapeuta Ocupacional no século XXI. Rev Baiana Saúde Pública. 2008;32(supl. 1):34-41.

6. Emmel MLG, Lancman S. Quem são nossos mestres e doutores? O avanço da capacitação docente em terapia ocupacional no Brasil. Cad Ter Ocup UFSCar. 1998;7(1).

7. Freire P. Pedagogia da autonomia: saberes necessários à prática educativa. 33a ed. São Pulo: Paz e Terra; 2006.

8. Lopes RE, Oliver FC, Malfitano APS, Galheigo SM, Almeida MC. XI Encontro Nacional de Docentes de Terapia Ocupacional: refletindo sobre os processos de formação acadêmica e profissional. Rev Ter Ocup Univ São Paulo. 2008;19(3):159-66.

9. Lopes RE, Malfitano APS. Perspectivas e desafios para a pesquisa em terapia ocupacional: uma análise do seu I seminário nacional de pesquisa. Cad Ter Ocup UFSCar. 2009;17(supl esp).

10. Lopes RE, Malfitano APS, Oliver FC, Sfair SC, Medeiros TJ. Pesquisa em terapia ocupacional: apontamentos acerca dos caminhos acadêmicos no cenário nacional. Rev Ter Ocup
Univ São Paulo. 2010;21(3):207-14.

11. Marcolino TQ. A dimensão pedagógica nos procedimentos de terapia ocupacional [Dissertação]. São Carlos: Programa de Pós-Graduação em Educação, Universidade Federal de São Carlos; 2005.

12. Oliver F, et al. Desafios da educação em terapia ocupacional na América Latina para a próxima década. Rev Ter Ocup Univ São Paulo. 2011;22(3):298-307.

13. Pimenta SG, Anastasiou LGC. Docência no ensino superior. 4a ed. São Paulo: Cortez; 2010.

14. Pimentel V, Mota DDCF, Kimura M. Reflexões sobre o preparo para a docência na pós-graduação em enfermagem. Rev Esc Enferm USP. 2007;41(1):61-4. http://dx.doi. org/10.1590/S0080-62342007000100022

15. Pinto SCA, Yokoyama AY. Currículo integrado na formação do terapeuta ocupacional para o sistema único de saúde: a construção coletiva do projeto pedagógico. Rev Baiana Saúde Pública. 2008;32(supl. 1):50-1.

16. Rosa SD, Emmel MLG. Reflexões sobre os diferentes papéis assumidos pelo terapeuta ocupacional enquanto professor universitário. Cad Ter Ocup UFSCar. 2001;9(1).

17. Shaurich D, Cabral FB, Almeida MA. Metodologia da problematização no ensino em enfermagem: uma reflexão do vivido no PROFAE, RS. Esc Anna Nery R Enferm. 2007;11(2):318-24. Disponível em: http:/www.redalyc.org/ articulo.oa?id=127715306021

18. Universidade de São Paulo. Pró-Reitoria de Pós-Graduação. Programa de Aperfeiçoamento de Ensino. São Paulo; 2012a [citado 29 ago. 2012]. Disponível em: http://www.prpg.usp. br/pt/interna1/pae.html.

19. Universidade de São Paulo. Pró-Reitoria de Pós-Graduação. Programa de Aperfeiçoamento de Ensino. São Paulo; 2012b. [citado 29 ago. 2012]. Disponível em: http://www.prpg.usp. br/pt/interna1/paeDiretrizes.html.

20. Zabalza MA. O ensino universitário: seus cenários e seus protagonistas. Trad. Ernani Rosa. Porto Alegre: Artmed; 2004. 